\title{
Management of Juvenile Nasopharyngeal Angiofibroma in a Referral Hospital in West Java, Indonesia
}

\author{
Yussy Afriani Dewi, Ifiq Budiyan Nazar \\ ${ }^{1}$ Department of Otorhinolaryngology, Head, and Neck Surgery Faculty of Medicine \\ Universitas Padjadjaran/Dr. Hasan Sadikin General Hospital Bandung, Indonesia
}

\begin{abstract}
Background: Juvenile nasopharyngeal angiofibroma (JNA) is a fibrovascular tumor originating from the supero-posterior area of the sphenopalatine foramen. This tumor is histologically benign, but is clinically malignant because JNA has potentially destructive spread extending to the skull base and the cranium. The aim of the study was to evaluate the management of JNA in Dr. Hasan Sadikin General Hospital Bandung, a referral hospital in West Java.

Methods: This was a descriptive retrospective study using medical record data of JNA patients during the period of 2011-2018. The stage of JNA was designated, based on the FISCH classification.

Results: There were112 JNA cases, consisting of 99\% male and 1\% female. Most of them (97\%) were aged 10-20 years old (median16 years old). The chief complaints were nasal obstruction (46\%) and recurrent epistaxis (36\%). Most of the JNA stage was stage II (43\%). Major feeding vessel of JNA was from an internal maxillary artery (IMAX) and ascending pharyngeal artery (28\%). Preoperative management was equal for ligation and embolization. The complication of embolization was local pain (75\%). The most surgical technique performed was the transpalatal approach (41.36\%). Blood loss in a different stage in JNA surgery with embolization was less than surgery with ligation. There were patients (10\%)with residual disease after 6 months follow-up.

Conclusions: JNA is essentially a disease of the adolescent males. The management of JNA patients is surgery, mostly using transpalatal technique. Preoperative embolization of JNA is a safe procedure, minimizes intraoperative blood loss, decrease the incidence of residual or recurrence, and shortening the duration of the surgery.
\end{abstract}

Keywords: Embolization, FISCH classification, internal maxillary artery, juvenile nasopharyngeal angiofibroma, ligation

\section{Introduction}

Juvenile nasopharyngeal angiofibroma (JNA) is a hypervascular, slow growing, and locally destructive tumor. The tumor is histologically benign, however, JNA is aggressive and destructive, spreading from sphenopalatine foramen with extension occurring into the osseous and soft tissue structures. ${ }^{1,2}$ The incidence of JNA is $0.05-0.5 \%$ of all headneck tumors, and is relatively higher in India and Egypt compared to America and Europe. In Asia and the Middle East, the incidence is around 1:5,000 and 1:60,000. The lesion mostly affects adolescent males with the highest incidence between 14-18 years old. ${ }^{3}$
The JNA presents clinically with nasal obstruction, recurrent epistaxis, facial numbness, ear fullness, rhinorrhea, cheek swelling, sinusitis, nasopharyngeal mass, headaches, visual changes, proptosis, and orbital involvement. ${ }^{1,2,4}$ The diagnosis of JNA is based on history taking and physical examination, confirmedbymultiplanarimaging studies such as Computed Tomography (CT) or Magnetic Resonance Imaging (MRI). ${ }^{5,6}$ The CT scan helps in better delineation of osseous involvement of tumor, while MRI is useful for assessing intracranial extension. Moreover, the CT angiography is used to define the tumor blood supply and the vascular composition of the tumor since the JNA is highly vascular and

Correspondence: Ifiq Budiyan Nazar, Department of Otorhinolaryngology, Head, and Neck Surgery, Faculty of Medicine, Universitas Padjadjaran/Dr. Hasan Sadikin General Hospital, Jalan Pasteur No. 38 Bandung, Indonesia, Email: ifiq82nazar@gmail.com 
predominantly blood supplied via the branches of External Carotid Artery (ECA), mainly from the internal maxillary artery (IMAX), multiple branches of ipsilateral ECA, contralateral ECA, and InternalCarotidArtery (ICA). ${ }^{2}$

Surgery is the mainstay of treatment for JNA. ${ }^{1,4,6}$ The surgical approaches are including transpalatal, lateral rhinotomy, facial degloving, or endoscopy technique., ${ }^{1,7}$ Since JNA is an aggressive tumor with a strong tendency to bleed, the surgical resection can be complicated by massive hemorrhage. An important advancement in treatment is preoperative intra-arterial embolization, which is now widely accepted and performed to reduce blood flow to the tumor. An alternative way is carotid artery ligation, as some hospitals may lack the facilities and infrastructure required for embolization. ${ }^{2}$ In addition to the management of JNA, the recurrence rate is also an important factor. Patients younger than 18 years have a recurrence rate of $48.2 \%$. The study exploring the characteristics of preoperative management of JNA, intraoperative blood loss, postoperative complications, and recurrence of JNA in Indonesia is still very limited. Therefore, our study aimed to evaluate the management of JNA in Dr. Hasan Sadikin General Hospital
Bandung, as a referral hospital in West Java Indonesia.

\section{Methods}

A descriptive retrospective hospital-based study was conducted in Dr. Hasan Sadikin General Hospital, a referral hospital in West Java, reviewing the management of JNA by collecting a medical records of patients with JNA from 2011 to 2018. The inclusion criteria were complete medical record data on patients underwent preoperative ligation before surgical resection (group A) and patients underwent preoperative intraarterial embolization before surgical resection (group B). All patients were operated by the same team of surgeon and evaluation of the blood loss was also conducted by the same team of nursing staff.

The classification of FISCH was used for staging. Stage I was designated as tumor limited to the nasopharynx and nasal cavity with no bone destruction, Stage II was designated as a tumor invading the pterygomaxillary fossa, the maxillary antrum, the ethmoid and sphenoid sinuses with bone destruction. Furthermore, stage III was designated as tumor invading

Table 1 The Distribution Chief Complains among Juvenile Nasopharyngeal Angiofibroma Patients (n=112) from Dr. Hasan Sadikin General Hospital year 2011-2018

\begin{tabular}{lcc}
\hline \multicolumn{1}{c}{ Chief Complain } & n & \% \\
\hline Nasal obstruction & 52 & 46 \\
Recurrent epistaxis & 40 & 36 \\
Headache & 11 & 10 \\
Protruding Nasal Mass & 8 & 7 \\
Proptosis & 1 & 1 \\
Facial swelling & - & - \\
\hline
\end{tabular}

Table 2 The Distribution of Major Feeding Vessel among Juvenile Nasopharyngeal Angiofibroma Patients based on CT Angiography

\begin{tabular}{lcc}
\hline \multicolumn{1}{c}{ Major Feeding Vessel } & Number of patients & $\mathbf{\%}$ \\
\hline IMAX & 23 & 21 \\
Ascending pharyngeal artery & 8 & 7 \\
IMAX \& ascending pharyngeal artery & 31 & 28 \\
Bilateral supply & 13 & 12 \\
Unilateral supply & 29 & 26 \\
Internal Carotid Artery & 8 & 7 \\
\hline
\end{tabular}

Note: IMAX= internal maxillary artery 


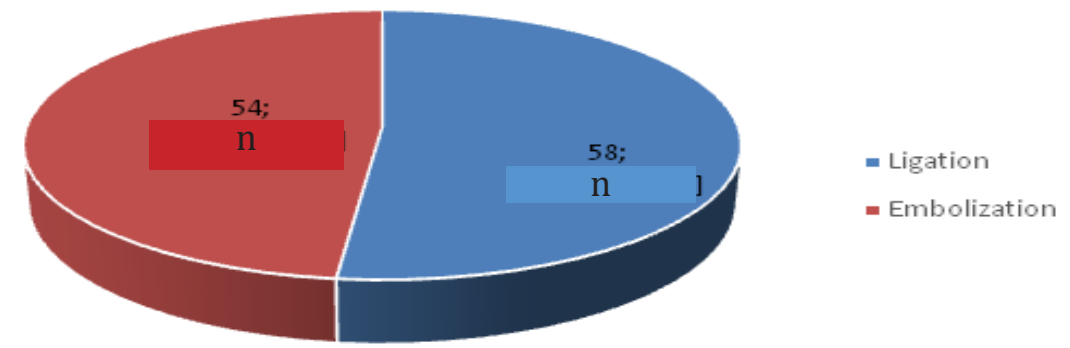

Figure1 Preoperative Methods in Juvenile Nasopharyngeal Angiofibroma Patients

the infratemporal fossa, the orbit, and the parasellar area, but remaining lateral to the cavernous sinus, and stage IV was designated as tumor with invasion of the cavernous sinus, the optic chiasm or the pituitary fossa.

Preoperative embolization and angiography were performed by experienced interventional radiologist. Surgery was performed within 24-72 hours after embolization. Surgical approach depended upon the stage of the tumor and approaches used were endoscopic approach, lateral rhinotomy, transpalatal and facial degloving. Blood loss was estimated by measuring the total fluid collected by suction and blood absorbed by gauze pieces. All data were described in percentage and presented in tables or figures.

\section{Results}

In total, there were 112 medical record data from 2011 to 2018, consisting of a male $(\mathrm{n}=111 ; 99 \%)$ and only one female. The age was predominantly $(n=109 ; 97 \%)$ between
10-20 years old (median 16 years old). The primary presenting symptoms were nasal obstruction $(n=52 ; 46 \%)$ and recurrent epistaxis ( $n=40 ; 36 \%)$ (Table 1$)$.

The tumors were staged according to the FISCH Staging, consisting of stage I $(n=29 ; 26 \%)$, stage II $(n=48 ; 43 \%)$, stage III $(n=27 ; 24 \%)$ and stage IV $(n=8 ; 7 \%)$, respectively. The CT angiography examination showed that $28 \%$ had blood supply from the internal maxillary artery (IMAX) and ascending pharyngeal artery, 26\% from the unilateral supply, and $12 \%$ from the bilateral supply. The IMAX was also shared in the arterial supply (21\%), and ascending pharyngeal artery (7\%) (Table 2).

Preoperative methods performed in 112 JNA patients were by ligation of the external carotid artery ( $\mathrm{n}=54 ; 48 \%)$ and by embolization $(n=58 ; 52 \%)$ (Figure 1), whereas surgical approaches for JNA were based on the stage of the tumor, which are transpalatal technique $(n=41)$, facial degloving $(n=40)$, lateral rhinotomy $(n=9)$, and closed approach or endoscopic resection) ( $\mathrm{n}=22)$.

Table 3 Blood Loss in a Different Stage of Juvenile Nasopharyngeal Angiofibroma Patients Based on Ligation and Embolizationa

\begin{tabular}{lccccccc}
\hline & \multicolumn{3}{c}{ Group A } & \multicolumn{3}{c}{ Group B } \\
\cline { 2 - 7 } & Stage & No. subjects & $\mathbf{\%}$ & $\begin{array}{c}\text { Blood Loss } \\
(\mathbf{m L})^{*}\end{array}$ & No. subjects & \% & $\begin{array}{c}\text { Blood Loss } \\
\text { (mL)* }\end{array}$ \\
\hline Stage I & 14 & 26 & 330 & 15 & 26 & 240 \\
Stage II & 23 & 43 & 660 & 25 & 43 & 450 \\
Stage III & 13 & 24 & 820 & 14 & 24 & 600 \\
Stage IV & 4 & 7 & 1200 & 4 & 7 & 900 \\
\hline
\end{tabular}

Note: Blood loss in the group underwent ligation (group A) and embolization (group B). * mean blood loss 
Table 4 Complications of Preoperative Embolization of among Juvenile Nasopharyngeal Angiofibroma Patients

\begin{tabular}{lcc}
\hline \multicolumn{1}{c}{ Complication } & Number of Patients & \% \\
\hline Local pain & 43 & 74 \\
Nausea & 8 & 14 \\
Local Subcutaneous edema & 5 & 9 \\
Temporary visual loss & 1 & 2 \\
Stroke & 1 & 2 \\
\hline
\end{tabular}

Intraoperative blood loss was measured by calculating the volume of blood that was collected in tubes. Description of intraoperative blood loss, vascular supply, and stage for a tumor that underwent ligation (group A) was presented side by side with those with embolization (group B). Preoperative embolization has been effective in decreasing intraoperative blood loss than artery ligation. Intraoperative blood loss from surgery with ligation ranges from 330-1200 $\mathrm{ml}$ and preoperative embolization ranges from 240-900 ml (Table 3).

Of the total 58 patients who performed preoperative embolization, several complications were found, predominantly as local pain ( $n=43 ; 26 \%)$ (Table 4). Postoperative complications and tumor recurrence remain the most tangible clinical outcomes. Postoperative imaging was conducted after 6 months of follow-up, however, some patients were lost in follow up. Of 47 patients from Group A (ligation group), 4 had a residual disease and 45 patients from Group B (embolization group), 7 had residual disease. No patients were dead in this case.

\section{Discussions}

This study reported that JNA patients registered in Dr. Hasan Sadikin General Hospital are predominantly (99\%) males, and a majority in the age group of 10-20 years with a median age of 16 years old. Our study is similar to a study that reported that the JNA has a predilection in the adolescent males with an age range of 7-21 years, and the highest incidence is between the age of 14-18 years. ${ }^{4}$ The etiology of this tumor is not known yet, however, there are several theories, one of those is due to hormonal imbalance such as excessive estrogen production or androgen deficiency. Based on this theory, there is a relationship between the tumor with gender and age of the patients. ${ }^{4,8}$

Patients with JNA present with a variety

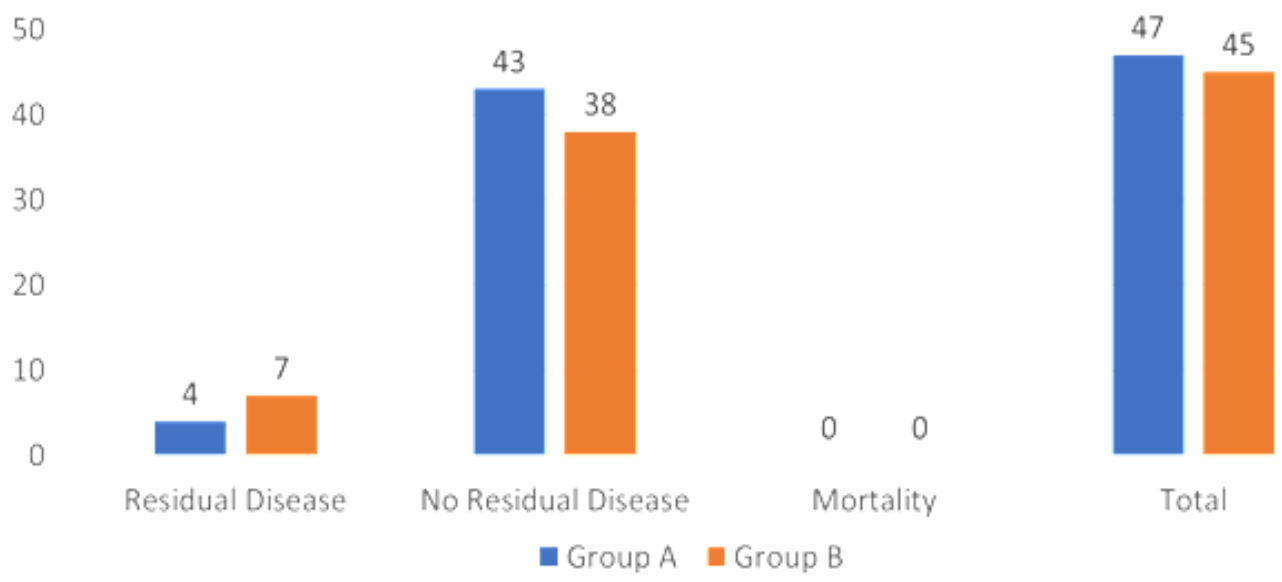

Figure 2 Postoperative Imaging as Follow-up after 6 Months of Surgery 
of major complaints. In this study, the most common complaints are nasal congestion and epistaxis similar to the symptoms of JNA reported such as nasal congestion (80-90\%), recurrent epistaxis (45-60\%), headache $(25 \%)$ that occurs when the tumor has spread to the paranasal sinuses, and facial swelling (10-18\%). Other symptoms such as anosmia, deafness, rhinolalia, cheek deformity, and palate swelling can also be found in patients with JNA. Nasopharyngeal angiofibroma is difficult to palpate, and a touch of a finger on the surface of the tumor can cause massive bleeding. ${ }^{8,9}$

Juvenile nasopharyngeal angiofibroma is hypervascular and predominantly supplied by the external carotid artery (ECA) circulation via the IMAX. They are associated with morbidity from local mass effect, bony erosion and remodeling of the bone, nasal obstruction, haemorrhage, and cranial nerve palsies. These tumors are surgically resected with the open procedure in ligation of ECA to decrease intraoperative blood loss. Preoperative embolization is performed to these tumors by interventional radiology and then resected by open surgery or by using endoscopy. The purpose of embolization is to decrease intraoperative blood loss. The blood supply for JNAs can be variable, with blood supply from multiple branches of the ECA, contralateral ECA branches, and small branches arising from the internal carotid artery (ICA). The CT angiography performed during the preoperative embolization procedure delineates the specific blood supply to JNA, allowing the surgeon to plan a surgical approach, anticipate areas of increased bleeding. ${ }^{2,10,11}$

The extirpation surgery technique that is often used is the transpalatal approach. The choice of surgical approach in JNA is generally based on the location, size, and extension of the tumor to the surrounding tissue, age and general condition of the patient, successful embolization before surgery and the experience of the surgeon. ${ }^{10}$

In this study, all cases managed with surgery as the main therapy for JNA such as transpalatal surgery, facial degloving, endoscopic surgery, and surgery using a lateral rhinotomy. Before the surgical removal of the tumor, external carotid artery ligation has been performed to some respondents, and others with embolization. Preoperative embolization of the JNA makes it easier to identify anatomical landmarks during surgery without massive bleeding and facilitating the procedure.
Consequently, preoperative embolization helps to reduce surgical morbidity. ${ }^{11-13}$

Endoscopic surgery has many advantages compared to traditional approaches, as this has a wider view of the tumor and anatomical landmarks from several angles become possible, better visualization of the interface between the tumor and adjacent bone and soft tissues. The result is more accurate and complete resection for control of bleeding can be performed. Another advantage of endoscopic surgery is that incisions for skin, mucosa, and osteotomies are unnecessary, affecting less the growth of the midface of adolescents. Incisions and closure were not needed, reduces the duration of the operation and postoperative complications, such as pain, dysesthesia, and trismus. ${ }^{2,14}$

All patients have been followed up with endoscopic examination and CT scan after six months postoperatively. Although most of them have no residual disease, some have residual disease. Predicting the recurrence of JNA is influenced by the age and the tumor stage of the patients. The higher chances of recurrence are younger and the later stage of JNA. Early diagnosis not only helps in better management but also prevents recurrences. ${ }^{15}$

The limitation of this study is that the data collected is from the medical records and follow up cannot be controlled, therefore, the follow-up data is not properly evaluated.

As a conclusions, JNA is a common disease of adolescent males, with the major feeding vessels are from the internal maxillary artery and ascending pharyngeal artery. The common chief complaints arenasal obstruction and epistaxis. The stage II has predominantly occurred. The management of JNA in West Java is surgery, mostly using a transpalatal technique. Preoperative embolization of JNA is a safe procedure without any substantial risk of neurological complications, that can minimize intraoperative blood loss, leading to a decreased incidence of residual or recurrence, and shortened operation duration.

\section{References}

1. Hodges JM, McDevitt AS, El-Sayed Ali AI, Sebelik ME. Juvenile nasopharyngeal angiofibroma: current treatment modalities and future considerations. Indian J Otolaryngol Head Neck Surg. 2010;62(3):236-47.

2. Oliveira JA, Tavares MG, Aguiar CV, Azevedo JF, Sousa JR, Almeida PC, et al. Comparison between endoscopic and open surgery 
in 37 patients with nasopharyngeal angiofibroma. Braz J Otorhinolaryngol. 2012;78(1):75-80.

3. Garça MF, Yuca SA, Yuca K. Juvenile Nasopharyngeal Angiofibroma. Eur J Gen Med. 2010;7(4):419-25.

4. Persky M, Manolidis S. Vascular tumors of the head and neck. In: Johnson JT, Rosen CA, editors. Bailey's Head and Neck Surgery: Otolaryngology, Volume $1.5^{\text {th }}$ Ed. Philadelphia: Lippincot Williams \& Wilkins ; 2014. p. 2021-8.

5. Zahara NP. Angiofibroma nasofaring belia dengan diagnosis awal hemangioma kapilare [internet] 2016 [cited 2019 September 28]. Available from: https:// docplayer.info/35679798-Angiofibromanasofaring-belia-dengan-diagnosis-awalhemangioma-kapilare-nimim-putrizahara.html

6. Alimli AG, Ucar M, Oztunali C, Akkan $\mathrm{K}$, Boyunaga O, Damar C, et al. Juvenile nasopharyngeal angiofibroma: magnetic resonance imaging findings. J Belg Soc Radiol. 2016;100(1):63.

7. Moideen SP. Staging systems for juvenille nasopharyngeal angiofibroma. [internet]. 2019 [cited 2019 September 28] Available from: https://www.e4ent. com/articles/staging-systems-juvenilenasopharyngeal-angiofibroma/

8. Anggreani L, Adham M, Musa Z, Lisnawati L, Bardosono S. Gambaran ekspresi reseptor estrogen $\beta$ pada angiofibroma nasofaring belia dengan menggunakan pemeriksaan imunohistokimia. Oto Rhino Laryngologica Indonesiana. 2011;41(1):8-16.

9. Bawa IPA, Dewi YA, Permana AD. Karateristik angiofibroma nasofaring belia di SMF/KSM Ilmu Kesehatan T.H.T.K.L/ RSHS Bandung tahun 2011-2016. In: Dewi YA, Ratunanda S, editors. Proceeding of The $2^{\text {nd }}$ World Head and Neck Cancer Day;
2016 July 27-28. Bandung, Indonesia. Bandung: FK Unpad; 2016. p. 313-21

10. Hutabarat I, Dewi YA, Permana AD. Efektifitas embolisasi preoperatif pada pasien angiofibroma nasofaring belia di FK UNPAD/RSHS Bandung Periode 2015-2016. In: Dewi YA, Ratunanda S, editor. Proceeding of The $2^{\text {nd }}$ World Head and Neck Cancer Day; 2016 July 27-28. Bandung, Indonesia. Bandung: FK Unpad; 2016. p 323-32

11. Tiwari PK, Teron P, Saikia N, Saikia HP, Bhuyan UT, Das D. Juvenile nasopharyngeal angiofibroma: a rise in incidence. Indian J Otolaryngol Head Neck Surg. 2016;68(2):141-8.

12. Ballah D, Rabinowitz D, Vossough A, Rickert S, Dunham B, Kazahaya K, et al. Preoperative angiography and external carotid artery embolization of juvenile nasopharyngeal angiofibromas in a tertiary referral paediatric centre. Clin Radiol. 2013;68(11):1097-106.

13. Sharma AK, Jain K, Manth $S$, Rawat DS, Mishra PC. A comparative study of preoperative transarterial embolized $\mathrm{V} / \mathrm{S}$ unembolized cases of juvenile nasopharyngeal angiofibroma. Int J Med Sci Educ. 2018;5(3):375-84.

14. Kasem MAHO, Awad AS, Al Bosraty HAM, Kamel AI. Preoperative embolization of nasopharyngeal angiofibromas: The role of direct percutaneous injection of cyanoacrylate glue in conjunction with particulate endovascular approach. Egypt J Radiol Nucl Med. 2016;47(4):1431-41.

15. Moorthy PNS, Ranganatha Reddy B, Qaiyum HA, Madhira S, Kolloju S. Management of juvenile nasopharyngeal angiofibroma: a five year retrospective study. Indian J Otolaryngol Head Neck Surg. 2010;62(4):390-4. 